\title{
13
}

\section{Mobilizing Political Support for the Brazilian Agricultural Research System}

\section{Eliseu Alves}

The question addressed in this paper is, from society's point of view, should agricultural research be considered a priority for the public sector? In other words, should a major objective be to increase total funds allocated to agricultural research and, if so, how should support from the public authorities be obtained?

The analysis is based on the idea that it is stress (or crisis), be it economic or social, that induces government to make decisions--clearly, not all decisions, but most of them, when heavy investments are needed (De Janvry 1973).

The question is, then, how do we detect signals of stress and make them known to society and government? Also, how does stress relate to lack of investment in research, and can society be motivated to support research? This paper addresses these questions. Brazilian agriculture supplies the background for the study, but the conclusions are intended to be applicable to other situations.

\section{PROCESSES FOR DEVELOPING AGRICULTURAL TECHNOLOGY}

For the purposes of this paper two processes for developing agricultural technology are relevant. What separates them is the presence or not of organized research (public or private).

The first process is illustrated by model A, figure 13.1. Organized research is not present. The growth in the stock of knowledge and technology is due to the accumulated experience of the farmers and to their ability 


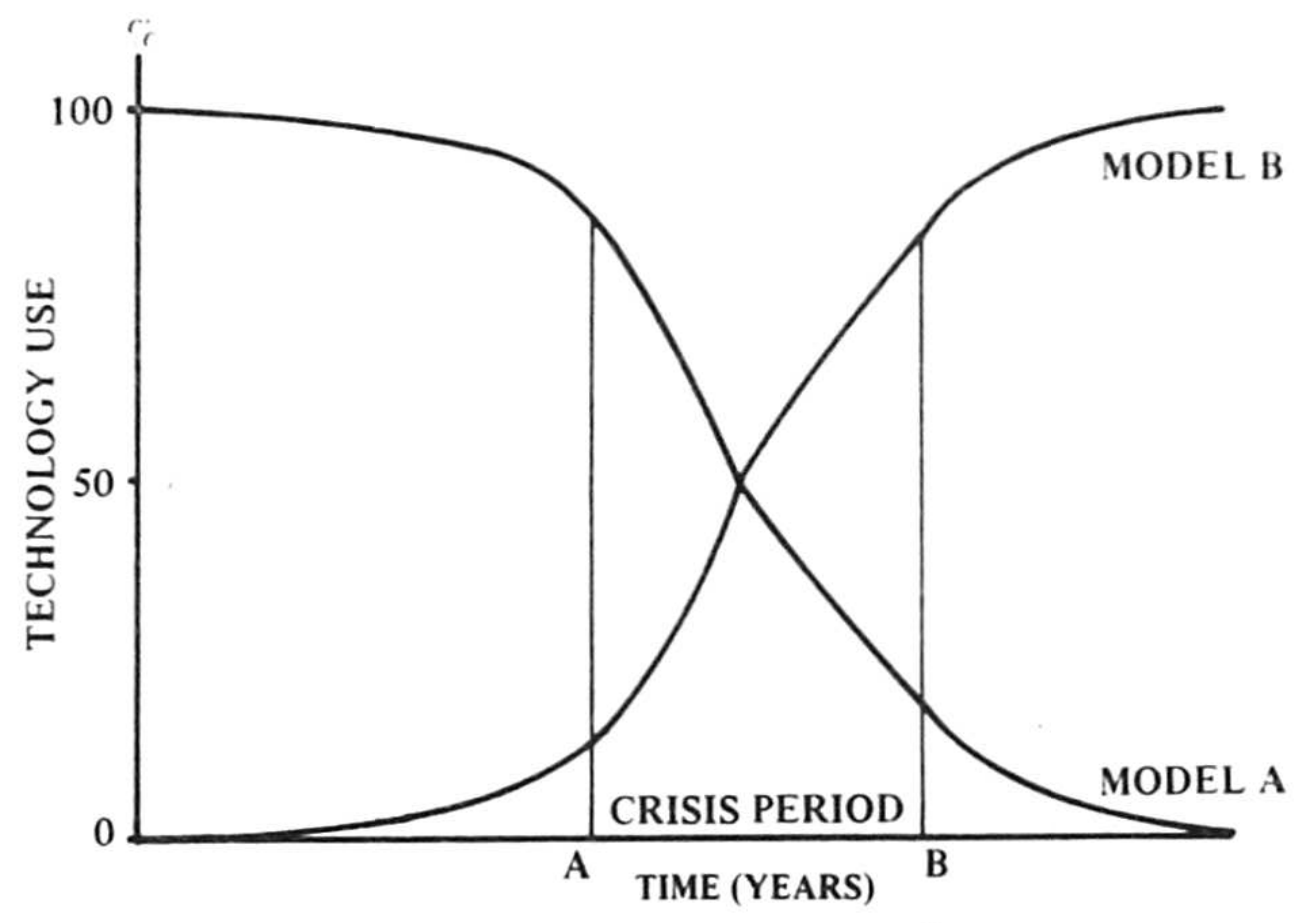

Figure 13.1. Models of technology in use by farmers

to import and adapt technology to the conditions of the country. The power to increase productivity (of labor or land) is small. The objective is to maintain the productivity level and to create conditions for expanding the cultivated area whenever possible. The process is limited, however, if the new environment is very different. For instance, the technology brought by the European and Asian immigrants was successful in developing agriculture in the northeastern and southern regions of Brazil but failed when it was applied to the Cerrados (Brazilian savannas--25 percent of Brazilian territory, most of it located in the central part of the country) and to the Amazon region. Those regions present problems peculiar to them that are very difficult to solve without the help of science.

Until the beginning of the century, this unsystematic way of generating knowledge (by trial and error) was responsible for the majority of technologies developed in Brazil. Here and in other developing countries its influence is still present, sometimes to a large degree. But it began to lose importance in the beginning of the 1960s.

The second process is illustrated by model $B$, figure 13.1. Knowledge and technology are generated by organized research (public and private). Technology is then science 
based. The transfer of knowledge and technology is through the research system, which adapts them to the needs of the country. The purpose of the technological development is to increase the productivity of land or labor, and to make possible the growth of the cultivated area when there is land to incorporate. Depending on the situation, one goal prevails over the other.

Figure 13.1 illustrates the agricultural technology development process. The vertical axis measures the amount of technology (models A and B) used by farmers. It varies from 0 to 100 (percent of farmers that use the technology generated by models A or B). The horizontal axis is time.

At the beginning, all technologies used by farmers are generated by model A. They begin to lose importance, slowly at first, then at growing speed when point $A$ is reached. Modernization of agriculture speeds up, and after point $B$ most of the technologies in use by farmers are generated by model B. Eventually a point may be reached when model $B$ is the only source of the generation of technology. After point B, agriculture is science based.

The interval $A B$ (fig. 13.1) indicates the period when stress (or crisis) is mounting. It coincides with a great acceleration of the agricultural modernization process. The crisis may be the consequence of a food deficit, the loss of the country's ability to export, or the disturbance of rural life when some farmers progress at a faster rate, improving their social status, while the great majority lag behind. In other words, income is being concentrated by the modernization process and land is in fewer hands. The rate of migration speeds up, and if the industrial and service sectors do not develop, unemployment and underemployment, with all of their consequences, emerge in the cities.

The stress is a consequence of society's delay in investing in research or in importing technology. The crisis is also a consequence of the lack of response of agriculture to a growing demand or to the increase in competition in international markets. How long the stress will last depends on the ability of society to remove the chief block to the modernization of agriculture, the lack of investment in research.

There is need for a great increase in the speed of agriculture modernization (at point $A$ and after it occurs) because investments were not made in the right amount in the previous period. Hence the crisis can be avoided if the government learns when model A loses the capacity to 
bring about supply growth according to the growth of demand and makes the necessary investments.

\section{TYPES OF CRISIS}

The crises are classified as the following types, which may be present at the same time:

Food Deficits. Demand for food is growing at a faster rate than supply and the country is not able to import food because of balance of payments problems brought about by a large accumulated deficit in foreign currency. This is the most serious type of crisis, in the sense of causing damages to economic and social systems.

The most important factors behind demand growth are population and per capita income increases. Urbanization shifts demand to such products as animal protein and fruits and vegetables. Edible beans, manioc, and other domestic products become less and less important. The need to export is another important factor. Among the factors that explain the lack of response of supply are investment in research and extension, price, credit, and export policies.

By helping to solve food crises, research institutions can show government and society the importance of increasing the investment in them.

Loss of Capacity to Export. Agricultural exports are an important sector of most developing countries. After the Second World War the developed countries experienced a fast growth in exports of agricultural products as the result of agricultural modernization and huge amounts of government subsidies. Since then, competition has mounted and prices have fallen. Since 1975, prices of the most important export commodities, soybeans, corn, wheat, sugar, rice, and cotton, have fallen to levels that are now the lowest in modern times.

The developing countries have not been able to meet this competition and, hence, are losing their position in international markets. Some of them are becoming net importers of food or are importing food at increasing rates.

The loss of important markets and the import of food trigger the mechanism of a deep crisis in rural areas that reflects over all society. Income in rural areas decreases and the rate of migration increases. The balance of payments worsens. Society sees in the import of food a loss of prestige and an increased vulnerability to fluctuation in international trade. 
LAND TENURE

The growth in rural population, the lack of employment opportunities in other sectors of the economy, and the concentration of land in the hands of a few are responsible for another type of crisis that is common in the developing countries: the pressure by peasants for land. When there is a food deficit and the migration rate is very high, society may see land distribution as the main cause of the crisis. Then comes the quest for agrarian reform as a way to modernize agriculture and to reduce income disparities. In modern times, research and extension are seen as important tools for the success of the program.

When there is a frontier where agriculture can expand, one way out of the crisis is to put more land into cultivation. This happens at the expense of investments to increase productivity. When research institutions face such a situation, two courses of action are advisable. First, demonstrate how much society loses because productivity does not increase; second, show that research is an important tool in solving problems posed by a new environment in which agriculture is expanding.

Factor Price Change. Factor price changes, or increasing costs of production, also cause stress. Farmers react by stimulating the generation of technologies that save the factor that has its price increased the most. Also, the research institutions are induced to shape their research programs according to the factor price changes. It is not only a question of reallocation of funds. The government is also induced to increase its investment in research. The literature on this subject is vast; one of the best references is Hayami and Ruttan (1985).

\section{GENESIS OF THE CRISES}

The factors that explain the crises vary according to type of crisis. For instance, the policy to expand acreage, coupled with high rates of migration to the cities and the restrictions of the immigration laws, causes labor to become relatively scarce to land and, consequently, shifts the factor prices. 
The discrimination against agriculture that is so common among developing countries, to foster industrialization, restricts the ability of agriculture to respond to demand increase and causes a growing food deficit, in conjunction with a loss of exporting capacity.

The policy to subsidize modern inputs through credit discriminates against small farmers and favors the concentration of land in fewer hands.

If the increase of productivity is the best avenue to increase supply and the government does not support research to the extent that it is needed, agriculture loses the capacity to grow and to compete in international markets.

From the standpoint of research institutions that want to see their funds increased, it is important to know the nature of the crises that are present and, moreover, to be able to foresee when they start, if they are not already present.

\section{SOURCES OF SUPPLY GROWTH}

Increases in agricultural production can be achieved by increasing output per unit area (yield), by increases in land area per worker, and by growth of the labor force (table 13.1).

Thus there are two paths for output growth: yield and area increase. They need not be mutually exclusive. However, from the standpoint of costs to society, one may be preferable to the other. If yield is preferable to area increase, and if the investments are made only to increase acreage, then $\mathrm{p}$ will be smaller for a given set of prices and technologies.

From table 13.2, which shows the change in the rate of output growth of Brazilian agriculture for four decades, it can be seen that acreage increase is the main source of growth, except for the last decade, when yield becomes the most important source.

Yield increase started at a very low level and recently speeded up to become the most important source. The opposite is true for acreage, which decreased in the last two decades.

About 66 percent of Brazil's agricultural land is not in agricultural use. The slowdown in acreage increase is a consequence of the difficult environment in which the new frontier, the Amazon region, is located. It is expensive to bring this land under production and tho anorntinn 
TABLE 13.1

Sources of Growth in Agricultural Production

The following identities are useful in identifying the sources of growth. The symbols are annual rates (geometric) of growth.

$p=(a+r)+[(a)(r)]$

$\mathrm{p}=$ production; $\mathrm{r}=\mathrm{yield} ; \mathrm{a}=$ acreage

$a=(t+k)+[(t)(k)]$

$t=$ area that each worker can cultivate;

$\mathbf{k}=$ labor force in agriculture.

The two identities may be combined to give:

$$
\begin{aligned}
p= & (r+t+k)+[(r)(t)+(r)(k) \\
& +(t)(k)+(r)(t)(k)]
\end{aligned}
$$

The bracketed terms measure the interaction effects, which tend to be small in relation to additive ones.

To increase acreage it is necessary to have $(t+k)+[(t)(k)]>0$. If $k<0$ (labor force in agriculture is decreasing), then it is necessary to have $t>|k+(t)(k)|$. This means that mechanization must be stimulated.

If $r=0$, which was common among the developing countries until the 1960s, production will grow only by acreage increase. If $t=0$, which was true also in some developing countries, production growth is equivalent to labor force growth.

If there is a technological barrier to acreage expansion or if the frontier is already exhausted, then $a=0$, and $t>0$ implies $k<0$. This means that labor is displaced, and the size of displacement varies with $t$.

costs of production there are higher than in any place else in Brazil. To these negative factors, one must add the high transport costs to the important markets of the country, which are far away. Nonetheless, acreage increase is one of the important sources of production expansion in 
TABLE 13.2

Decomposition of the Geometric Rates of Growth of Production between Acreage and Yield, Brazil, 1940-1980

Sources of

Growth

\begin{tabular}{cccc}
\multicolumn{4}{c}{ Decades } \\
\hline $1940-50$ & $1950-60$ & $1960-70$ & $1970-80$ \\
$\%$ & $\%$ & $\%$ & $\%$
\end{tabular}

Yield ( $\mathrm{r}$ )

.53

1.58

1.89

3.49

Acreage $(t+k)$

2.58

4.16

3.46

2.96

Production (p)

3.11

5.74

5.35

6.45

Source: Adapted from Alves (1995).

Note: The interaction effects were small and were included in $r$ and $t+k$.

Brazil, and research institutions need to show society how they can contribute to solving the problems associated with the new frontier.

\section{ACREAGE OR YIELD INCREASE}

Figure 13.2 clarifies the conflict between acreage and yield growth as ways to increase production. The vertical axis measures acreage cost and the horizontal axis yield cost. The path MR indicates the social costs to obtain one additional unit of production through yield and acreage. Each point over the path reflects a different date. Time increases from $O$ on. Line $O C$ is the locus of points where the two costs are equal.

Included in acreage are the usual costs of investments to bring land into production, such as roads, infrastructure, forest clearing, etc. Included in yield are the costs of research and extension, credit subsidies to stimulate the diffusion of innovations, and the usual costs of production.

In the beginning, acreage costs grow slowly because the land first put into production is more fertile and easier to cultivate. Costs then increase at a faster rate because the new land is far from markets, is difficult to clear, and is not as fertile as the older areas. Such 


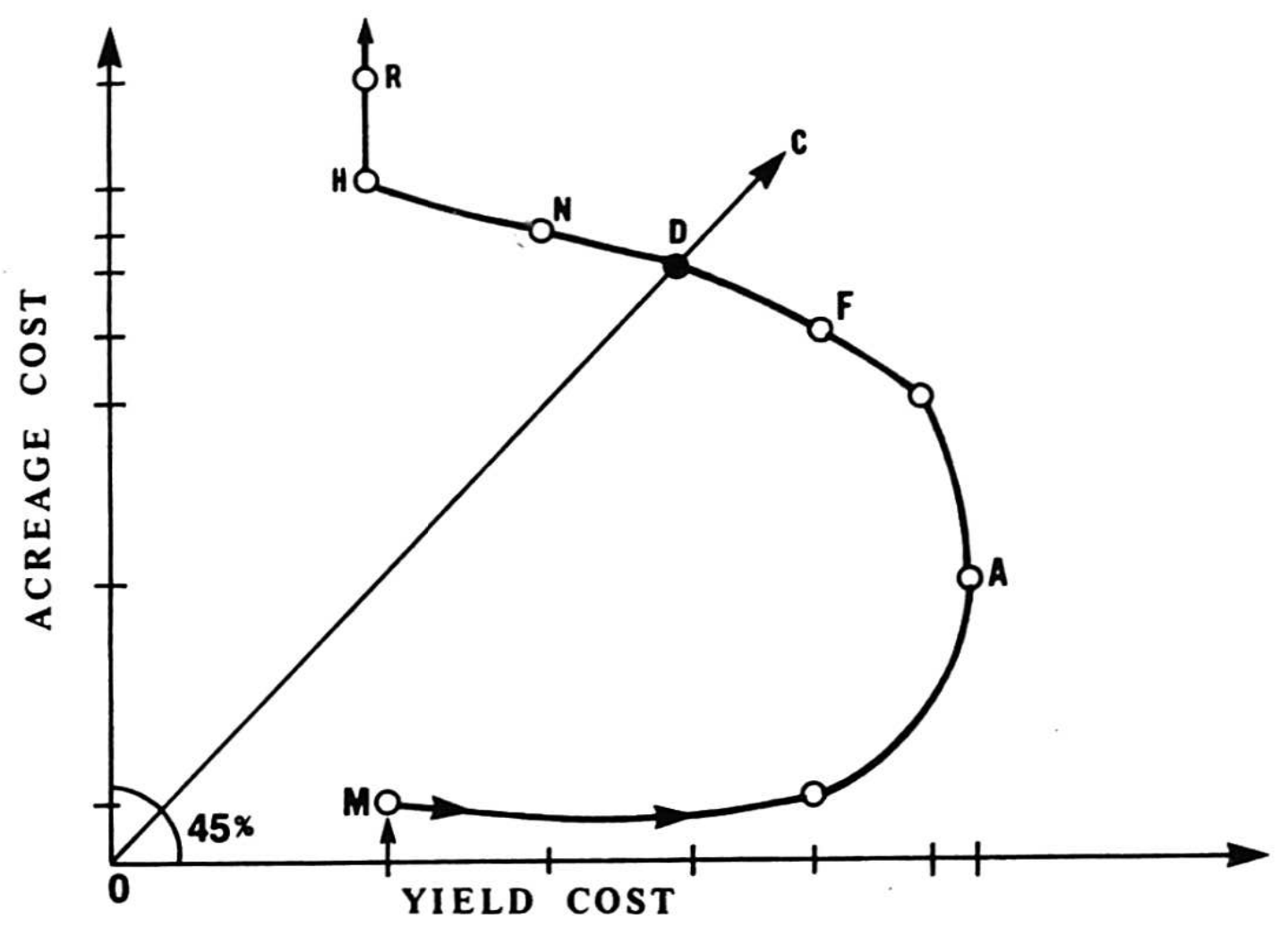

Figure 13.2. Social cost to obtain one additional unit of production by yield and acreage increase

etc., can reduce such costs by delaying the increase in acreage costs to produce one additional unit of output.

Yield cost grows fast in the beginning. Traditional technologies, model $\mathrm{A}$, have very limited power to increase yield. The possibilities for importing technologies are also very restricted. When the country shifts to model B and improves its capacity to generate knowledge and technologies, yield cost decreases and eventually stops. At point $D$, yield cost and acreage cost are equal. At point A, yield cost begins to decrease and the rate of decrease speeds up after that point.

Eventually the frontier is exhausted and there is no peaceful way to incorporate additional areas. This happens at $\mathrm{H}$, when acreage cost grows without limit. At this point yield cost reaches a minimum and the path becomes vertical. The convex part of the path MR faces the line OC. If a country is at a point below line $O C$, let us say point $A$, one additional unit of output costs more if obtained through yield than through acreage increase; above line $O C$, the opposite occurs.

Long before the frontier is exhausted, it may be cheaper to increase output by yield increase, although the 
country may be pursuing an acreage increase policy, the most common policy among the developing countries. Under the acreage increase policy the output of agriculture would grow by a smaller amount, sometimes much smaller, than if a yield increase policy had been chosen. There are many political pressures for land expansion and very few for yield improvement. The reasons are: tradition (historically this is what has been done); pressures for land by peasants who want more land to cultivate; the high cost (financial cost) of establishing or expanding research and extension institutions; the false idea that research only brings results in the long run (a confusion between research project and research institution--the latter produces results every year).

The acreage increase policy leads the country to a food deficit and to fewer and fewer exports, worsening balance of payments problems and impoverishing rural areas, with a consequent increase in migration. Urban and rural crises are set free. When the line $O C$ is crossed, if investments in yield increase have not previously been made, the country will be moving toward crisis. It is also important to note that it is difficult to convince the authorities to invest in research when the point reached is below line OC. The research institutions established in this period may not survive because of lack of support.

To take advantage of the crisis to improve the support to research institutions, it is important to know whether or not the country is urban. Different strategies are used, depending on whether the political power is in the hands of the urban or the rural people.

Figure 13.3 contains two paths. Path $\mathrm{L}_{1}$ is for a country that created employment opportunities in the cities. It was able to continuously attract the rural population. Initially, a majority of the population was located in rural areas. Migration, sometimes at growing rates, shifted the population to the cities. At line OC, urban population equals rural population, and then becomes larger. Countries that followed path $\mathrm{L}_{1}$ also pursued a policy of draft industrialization. The idea of the policy was to apply the savings (internal and external) to the industry energy and road construction sectors and let agriculture grow by acreage expansion, with a very small amount of investment in modernization, to avoid competition with the urban sectors for the saving. Points above line $O C$ (refer to figure 13.2) were reached before the agriculture policy shifted to yield increase. 


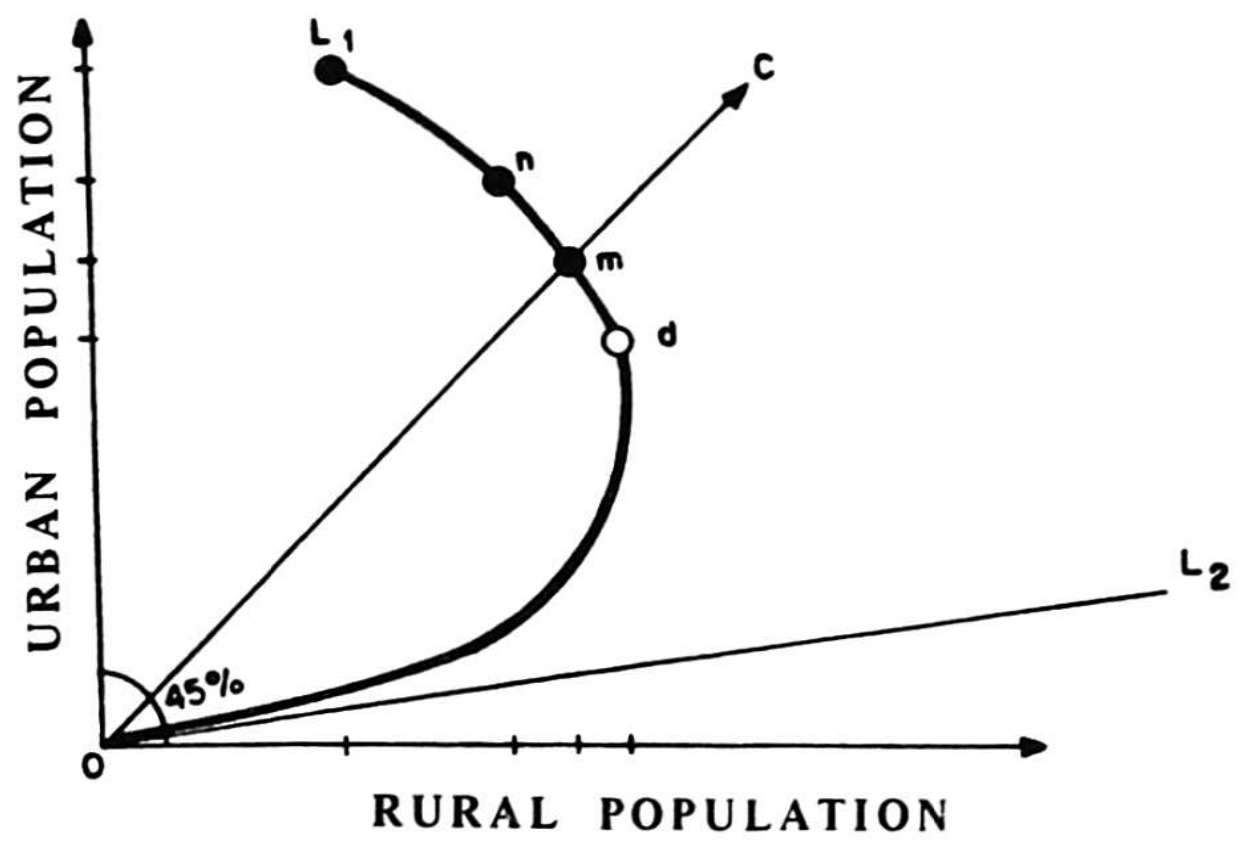

Figure 13.3. The growth of urban and rural population: Number of inhabitants

When line OC is reached, political power also shifts to the cities--to the leaders of the industrial and financial sectors and to organized labor, which are political groups with the same interests. These groups are important targets for obtaining research support. It is important to give them information that will lead to their understanding that the urban crisis will worsen if the agricultural policy does not shift to yield increase and that without investments in research this shift cannot be achieved.

The themes for this understanding are the following:

1. Linkages between violence and food deficit

2. Reduction of worker productivity and ability to learn as a consequence of nutritional problems

3. Loss of the capacity to export

4. Increase in migration as a consequence of income problems in rural areas

5. The need to import food and the consequent devastating effects on the balance of payments and the morale of the country

6. The worsening of equity problems as a consequence of the increase in food prices

Competent professionals, hired from the press, should be used to reach the target groups. The media should include television, newspapers of wide circulation, and radio. The message should interest the urban population, 
but not to the neglect of rural people. On the contrary, the role of farmers in solving the urban crises should be stressed (Alves 1984).

Path $L_{2}$ is for a country that preferred to stay rural or that could not industrialize. The leadership of the country is predominantly rural or has strong interests in rural areas, where the sources of political power are located.

It is necessary to take into account two groups of countries. The first is densely populated with the frontier already exhausted. The people have a long agricultural tradition and a culture built around religion. Their grasp of the meaning of the world and of things is from the general to the particular. Their reasoning is much more intuitive than analytical. Here, it is not easy to create an environment favorable to science. Their methods, sometimes, are not democratic; they may or may not work, and most of the time they do not work.

They are poor countries; the level of savings is low. The investment in research institutions needs the support of the donor community. Hence to show the relevance of research it is important not to overlook the donor community. On the other hand, the possibilities for internal financing should not be neglected.

One needs to be careful not to present science as opposed to religion and to avoid comparisons, whether implicit or explicit, between scientific and religious reasoning.

The themes to be discussed are linked to poverty problems, famine, well-being, and the role that modern agriculture can play in improving the income in rural areas. In those societies, the question of equity is a major issue and, hence, should be addressed carefully. The press, churches, and meetings with important leaders are the main communication channels with society.

The second group of countries has not yet exhausted the frontier through which agriculture can expand. However, the frontier presents problems to agricultural production and may require huge investments to become productive. This is a theme for discussion, as is the question of how science can be helpful in developing the frontier land. One needs to be careful in adopting scientific reasoning to the problems since the farm people tend to be suspicious of the paradigms of science. 


\section{SIGNS OF CRISES}

Four types of crises have been analyzed: food deficit, loss of export capacity, land tenure, and factor price changes. Simple statistics may be used to substantiate them. The growth of output ( $p$ ) can be computed, also yield and acreage. The identity given below is true for each period:

$$
p=r+[(a)(r)]
$$

$a=$ annual rate of growth of area (geometric). If there are statistics of the labor force, identity (1) can be applied. Yields can be computed on a crop by crop basis. With this approach the effects of crop substitution on yield are lost. The evidence shows whether or not yields are stagnated, what the contribution of acreage to output growth is, and, finally, how the contribution of acreage splits into labor productivity and labor force increase.

It is much more complicated to evaluate whether line $O C$ in figure 13.2 has been crossed. In other words, where are the returns to investment higher: through acreage or yield increases? Statistics on the rate of return to research and extension provide some hints. But the best approach is through a direct evaluation of the return of investment in acreage or yield growth. The literature is lacking in this respect.

\section{CONCLUSION}

It has been shown here how crises can be helpful in obtaining society's support for research. The ideas discussed are very general so that they can be broadly applied. A given research institution, however, should find and use the best strategy for its own situation. The point to be stressed is that support for research institutions can be increased if the correct strategies are chosen, and this involves the discussion of broad economic and social issues. 


\section{REFERENCES}

Alves, E.R.A. "Making Agricultural Research a Priority for Public Investment." In Brazilian Agriculture and Agricultural Research, edited by Levon Yeganiantz, 175-89. Brasilia: EMBRAPA, 1984.

"Produtividade Animal e Novas Tecnologias." In Pesquisa Agropecuaria - Novos Rumos, edited by Levon Yeganiantz, 93-157. Brasilia: EMBRAPA, 1985.

De Janvry, A. "A Socioeconomic Model of Induced Innovations for Argentine Agricultural Development." Quarterly Journal of Economics 87(3)(1973): 410-35.

Hayami, Y., and V. W. Ruttan. Agricultural Development: An International Perspective, rev. ed. Baltimore: Johns Hopkins University Press, 1985. 